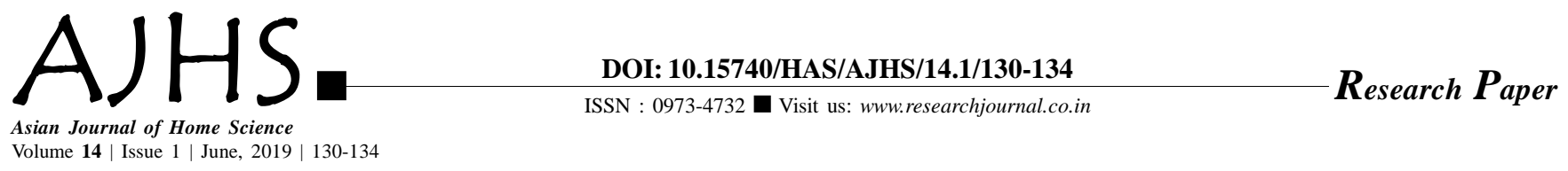

\title{
A study to assess the effectiveness of developed multimedia package regarding unintentional injuries among mothers of Udaipur district, Rajasthan, India
}

\section{Preeti Verma}

Received: 18.03.2019; Revised: 27.04.2019; Accepted: 07.05.2019

Author for correspondence :

\section{Preeti Verma}

Department of Home Science, Government Meera Girls College, Udaipur (Rajasthan) India Email: preetidv74@gmail.com

\begin{abstract}
Injury prevention is an incredible beneficial community welfare approach and addressing the mother's knowledge base is the most hopeful one to battle the injury problem. A custom- made package will very well interweave into the existing knowledge of the mothers to stand by to safe guard their children from injuries and above all for its wider applicability measuring the impact or effectiveness of package was the objective of the present study. Three non government schools from Udaipur, Rajasthan were selected. A stratified purposive sampling technique and self designed questionnaire was used. The study population was 180 mothers. In the first phase of study response related to fifty-nine closed ended questions on five prevalent unintentional injuries i.e. Burns, scalds and electrocution, poisoning, falls, slips and trips, drowning and road traffic injuries were elicited. The second phase was related to self rating of the knowledge level of respondents towards various unintentional injuries and their causes among children on a five point likert scale. The cronbach's alpha co-efficient for establishing scale reliability was used and experimental research design was used. In third phase the respondents were exposed to DVD and a manual was given to carry home. After a gap of one month, the post test of the respondents was conducted. Frequency, percentage, mean score were used to analyze data statistically. Independent sample t-test was applied to study the difference between the knowledge of mothers about unintentional injuries before and after exposure to MMP (DVD and Manual). The entire hypothesis was tested using paired sample ttest assuming unequal variance at 5 per cent level of significance ( 2 tailed). The statistical analysis was made with SPSS 16.0 statistical software. After the intervention through MMP, the mean knowledge scores were in the range of 4.67 to 4.94 . Consequently, it can be concluded that now respondents have extreme knowledge about various unintentional injuries among children and MMP was effective in increasing the knowledge of mothers.
\end{abstract}

KEY WORDS: Effectiveness, Multimedia Package, Unintentional injuries, Mothers, Children

- HOW TO CITE THIS PAPER : Verma, Preeti (2019). A study to assess the effectiveness of developed multimedia package regarding unintentional injuries among mothers of Udaipur district, Rajasthan, India. Asian J. Home Sci., 14 (1) : 130-134, DOI: 10.15740/HAS/AJHS/14.1/130-134. Copyright@ 2019: Hind Agri-Horticultural Society. 